without recourse to the courts might reduce the already limited deterrent effect of litigation. The capriciousness of the present system would not be reduced at all because the criteria for deciding who would be compensated would be exactly as now. The new system might do something to reduce costs and delay, but the effect is likely to be minimal: as the consultation document says, $95 \%$ of negligence cases are currently settled out of court, and the $5 \%$ that go to court are the difficult ones that are least likely to be settled by arbitration.

What we need is not cosmesis but a cost effective no fault system combined with a strategy for reducing medical accidents. Britain could have a system like the Swedish one for about $£ 50 \mathrm{~m},{ }^{8}$ almost exactly the same as the amount paid out by the NHS for medical negligence in $1990 .^{6}$ And a
Swedish style system would mean that many more people were compensated with far less of the money ending up in lawyers' pockets.

Editor, $B M \mathcal{F}$

RICHARD SMITH

1 Harvard Medical Practice Study. Patients, doctors, and lawyers: medical injury, malpractice litigation, and patient compensation in New York. Boston: Harvard Medical Practice Study, 1990.

2 Smith R. The epidemiology of malpractice. BMF 1990;301:621-2.

3 Royal Commission on Civil Liability and Compensation for Personal Injury. Report. London: HMSO, 1978. (Cmnd 7054.) (Pearson commission.)

4 BMA. No fault compensation. London: BMA, 1987.

5 Dyer C. No fault compensation. BMF 1988;297:939-40.

6 Department of Health. Aribtration for medical negligence in the National Health Service. London: Department of Health, 1991 .

Department of Health, 1991.
Dyer C. Pressure for no fault on three fronts. BMF 1990;301:1010-1.

8 Ham C, Dingwall R, Fenn P, Harris D. Medical negligence: compensation and accountability. London: King's Fund Institute, 1988.

\title{
NHS reforms: the first six months
}

\section{Judgment suspended}

Only those who believed their own prophecies of doom about the changes in the NHS will be surprised by the NHS Management Executive's report on the first six months of the experiment. ${ }^{1}$ The NHS, quite predictably, went on much as before. The management executive's roll call of statistics provides a reassuring picture of a service that continued on much the same trajectory as in previous years, with an increase in the number of patients treated and a reduction in long waiting times. No doubt the report will be much invoked in the election campaign that has already begun. But what does it tell us about the success, or otherwise, of the government's strategy? And what are its wider implications for the debate about health care policy?

One conclusion can be drawn with some confidence. This is that the problems of transition-of introducing an extraordinarily complex set of changes - have been managed with remarkable success. In a sense, the report is a monument to the dedication and resilience of the NHS's staff. Instead of retreating into sullen resentment of the changes imposed on them they have clearly risen to the challenge of change. There does not seem to have been the sudden, catastrophic collapse in morale predicted by the opponents of the government's policies, which would surely have been reflected in the performance of the NHS as a whole.

But all that this indicates is that exaggeration tends to rebound on its authors. Apocalyptic prophecies are all too easily discredited when the end of the world (or of the NHS) does not arrive. The real question is how, over time, are we to evaluate the impact of the changes? The point can be simply illustrated. The management executive's report predicts that the number of inpatients treated will rise at a rate of $1.5 \%$ this year. This compares with an annual average increase of $2 \cdot 0 \%$ between 1978 and 1988, which, however, fell to $1 \cdot 2 \%$ in the last three years of the period. ${ }^{2}$ So it would seem possible to present the post-change statistics as showing either a decline in the secular trend or an improvement on previous years. And the interpretative ambiguity would be compounded, of course, if account was taken of the problems entailed in generating accurate and comparable data over time and the relation between NHS outputs and the input of funding.

What, in any case, should be the currency of evaluation? The NHS's productivity is, clearly, only one dimension of performance, although the Audit Commission's recent report suggests that there is much scope still for improvement. ${ }^{3}$ Another dimension is the NHS's capacity to reduce waiting lists and times: these are notoriously difficult to interpret, ${ }^{4}$ and concentrating on them may have perverse effects. The changes were after all designed to have wide ranging effects, among them the promotion of greater responsiveness and choice as well as of higher standards and quality. Here, without agreed criteria for assessing progress, there is a danger that the NHS will fall victim to a battle of case studies or anecdotes.

So, for example, the management executive's report cites several success stories, such as the introduction of specified standards for appointments and the use of various devices for eliciting consumer opinions. It can also draw on the results of a survey of patients of trust hospitals, ${ }^{5}$ which showed increased satisfaction. The critics of the NHS reforms, however, will no doubt be able to fire off a salvo of counteranecdotes, with hospital trusts running into financial trouble and patients denied extracontractual referrals. What this sort of approach cannot tell us is whether such instances reveal general trends or are aberrant examples, whether they reflect problems of transition or indicate flaws inherent in the design of the post-1989 NHS.

There is a further difficulty in coming to any conclusion about the success or failure of the NHS reforms on the basis of the management executive's report. If the NHS weathered the first six months of the changes relatively successfully, as it undoubtedly did, does this indicate that all is set fair for the future or that it was exploiting and using up the capital of dedication built up over the previous 40 years? In short, short term effects cannot yield a judgment about the long term impact of the changes. This point applies with perhaps special force to some of the unanticipated effects of the reforms, notably the changing balance of power between general practitioners and hospital doctors: the full effects of this will clearly take time to work themselves through. The dangers of rushing into premature evaluation are just as great as those of knee jerk predictions of disaster.

One conclusion to be drawn from the management executive's report may, therefore, be that there is an urgent need to develop a long term strategy of evaluation. Rightly or wrongly, the executive's half term report has been widely seen, and contested, as a contribution to political debatea reaction accentuated by the approach of a general election 
but probably inevitable even in a more relaxed political climate, given the emotions roused by the NHS reforms.

As the debate is not likely to be ended by a general election - and might even be intensified if a Labour government was to modify the system once again - there seems to be a strong argument for trying to generate a consensus about the criteria to be used in evaluating whatever policies are pursued and about the appropriate timescale. Such an enterprise might, perhaps, be a task for the all party health committee of the House of Commons after the election; alternatively, foundations might usefully sponsor a consensus conference. We should not be too optimistic about the outcome. There is no formula for resolving controversy over policy by an appeal to statistics: politics drive data, rather than the other way round. ${ }^{6}$ It might, however, at least be possible to produce agreement on a language and grammar of evaluation that would allow disagreements to be discussed more fruitfully than at present.

Professor of Social Policy,

Centre for the Analysis of Social Policy,

University of Bath, Bath BA2 7AY

1 NHS Management Executive. NHS reforms: the first six months. London: Department of Health, 1992.

Chancellor of the Exchequer. Chapter 13-Department of Health. The government's expenditure plans 1990-91 to 1992-93. London: HMSO, 1990. (Cm 1013.)

Audit Commission. Lying in wait. London: HMSO, 1992.

4 Yates J. Why are we waiting? Oxford: Oxford University Press, 1987.

5 Martin Hamblin Research. Attitudes among patients leaving trust hospitals. London: Martin Hamblin Research, 1991.

6 Wildavsky A, Tenenbaum E. The politics of mistrust. London: Sage Publications, 1981.

\section{Aneurin Bevan on the NHS}

\section{His commitment was deep, personal, and romantic}

"What we are doing is now being watched by the whole world," said Aneurin Bevan to a meeting of the Executive Councils Association at BMA House in October 1948. "This is the biggest single experiment in social service that the world has ever undertaken." More than 40 years on, the NHS looks somewhat battered and tarnished-less the envy of the world than an undermaintained (though still imposing) national monument.

Robin Cook is under pressure to redefine what the Labour party would do if it turned out to be the next custodian of this edifice. For that purpose he will need to look forward to the stresses and strains of the 1990s - the requirement for a flexible, adaptive use of resources in line with the changes in medical science and in demography and shifts in patterns of care towards a less paternalistic model. But he will want to modify the NHS in ways that are true to its original intent. It is therefore timely to have readily available Charles Webster's new edition of Bevan's speeches and memoranda on the NHS. ${ }^{\prime}$

Bevan's personal contributions included a blend of ruthless determination over what he saw as the essentials, along with a willingness to compromise over detail. Though the wartime coalition Cabinet had wanted a publicly funded set of health services with universal access, Bevan's two predecessors as minister had failed to find credible ways to weld together the public and private elements of the prewar system. ${ }^{2}$ They made the mistake of presenting detailed plans for consultation with the many interest groups concerned, their designs becoming more and more hopelessly baroque in the attempt not to offend anyone. Bevan would have none of it. His basic design - to achieve a comprehensive service by nationalising the hospitals under a regional management structure reporting through him to parliament - was fixed, to be defended only in the House of Commons and not a matter for negotiation outside it. On the detail, however, he was surprisingly flexible: hence the failure to integrate the teaching hospitals or general practice fully into the structure of the service, the perpetuation of private beds in public hospitals, and the system of distinction awards for senior hospital consultants.

Public oratory generally does not read well on the printed page. Nevertheless, Bevan's commitment to the values of the NHS was deep, personal, and romantic. "No society can legitimately call itself civilised if a sick person is denied aid because of lack of means." Or, more oratorically, "Society becomes more wholesome, more serene, and spiritually healthier, if it knows that its citizens have at the back of their consciousness the knowledge that not only themselves, but all their fellows, have access, when ill, to the best that medical care can provide." 3

These ideals are as relevant today as they were in 1948 and in many ways even more testing. Perhaps Bevan can be faulted (along with many others) for failing to recognise the public expenditure problems that will always be posed by the NHS. But there are many indications in his speeches and papers that he foresaw the difficulties of balancing local influence with central control, that he wanted members' appointments throughout the NHS to be non-political, that he would have preferred to make the costs of capital explicit and spread them over a number of years, that he wished to recommend the use of generic drug equivalents, and that he foresaw a problem in transferring payments between authorities for cross boundary flows. The reflection that "Resources were fully employed, and more for some could only be achieved by producing more or giving up something," is at least as relevant for the next decade in health care as for any other period in the history of the NHS. So is the remark that "This is a very great test of the maturity of the British people" - if people demand more than they need they will be standing in the way of those who need it more. They must "use this thing as though it were their own-because it is in fact their own."

Robin Cook needs to stand by Bevan's fundamental commitment to a collective approach to health care while being as far sighted, pragmatic, and developmental as Bevan actually was. The left must not let its vision of the NHS be stuck in a time warp. Certainly Bevan himself would not have allowed this to happen.

ROBERT MAXWELL

Chief Executive,

The King's Fund,

London W2 4HT

Webster C, ed. Bevan on the National Health Service. Oxford: Wellcome Unit for the History of Medicine, 1991

Pater JE. The making of the National Health Service. London: King's Fund, 1981.

3 Foot M. Aneurin Bevan Vol 2 1945-1960. London: Granada, 1975. 